\section{CHEMISTRY OF BLEOMYCIN. XXII \\ INTERACTION OF BLEOMYCIN WITH NUCLEIC ACIDS, \\ PREFERENTIAL BINDING TO GUANINE \\ BASE AND ELECTROSTATIC EFFECT \\ OF THE TERMINAL AMINE}

Sir:

The bleomycins are glycopeptide antibiotics isolated from Streptomyces verticillus ${ }^{1)}$. This family of antibiotics exhibits high antitumor activities and has been used in the treatment of human neoplasms. Bleomycin (BLM) causes strand scission of DNA in vitro as well as in vivo. We have studied BLM binding to various nucleic acids using fluorescence spectroscopy technique which was introduced by CHIEN et al. ${ }^{2}$

Uncorrected fluorescence emission spectra were taken with a Hitachi fluorescence spectrometer, Model MPF-4. All fluorescence spectra were measured in $15 \mathrm{~mm}$ Tris- $\mathrm{HCl}$ buffer (pH 7.6) containing $15 \mathrm{~mm} \mathrm{NaCl}$ and $1.5 \mathrm{~mm}$ EDTA, at $20^{\circ} \mathrm{C}$, in a cuvette with a $1-\mathrm{cm}$ light path. To

Fig. 1. Fluorescence spectra of bleomycins and their related compounds

Concentration of samples $7.5 \times 10^{-6} \mathrm{M}$ in $1.5 \mathrm{~mm}$ EDTA, $15 \mathrm{~mm} \mathrm{NaCl}, 15 \mathrm{~mm}$ Tris- $\mathrm{HCl}$ ( $\mathrm{pH} 7.6$ ), excitation at $290 \mathrm{~nm} .(+\mathrm{Cu})$ means copper-complex and the others are metal-free.

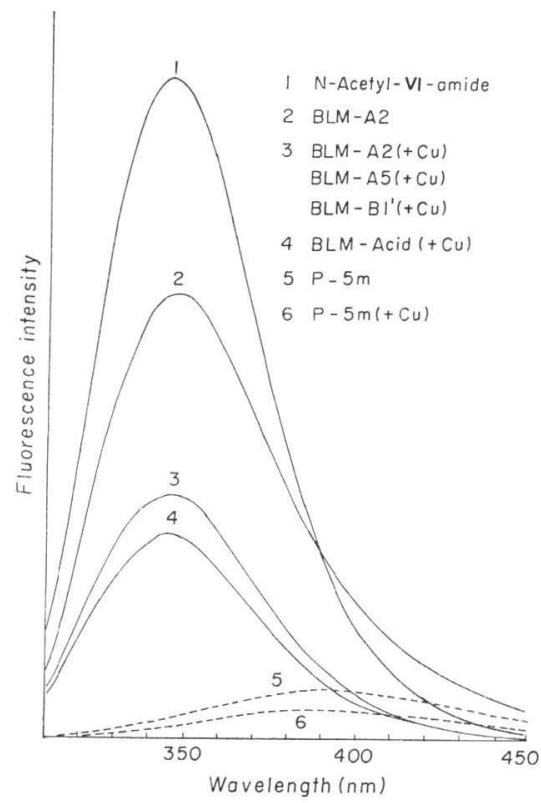

confirm the assignment of the fluorescence emission maximum of BLMs at about $350 \mathrm{~nm}$ to the bithiazole chromophore ${ }^{2)}$ and to characterize the intensity of the fluorescence, the spectra (Fig. 1) of BLMs in metal-free and copperchelated forms, copper-complex of bleomycinic acid (BLM-acid) ${ }^{3,4)}$, N-acetyl-VI-amide ${ }^{5)}$ (the smallest model compound for the bithiazole chromophore of BLM, see Fig. 2) and P-5m (a biosynthetic intermediate of BLM, unpublished, see Fig. 2) in metal-free and copper-chelated forms were taken by excitation at $290 \mathrm{~nm}$. All compounds containing the bithiazole chromophore showed maxima at about $350 \mathrm{~nm}$ although they had different fluorescence intensity, whereas P-5m which does not contain the bithiazole chromophore did not show the maximum at $350 \mathrm{~nm}$. BLMs which contained different terminal amines showed the same intensity. A metal-free BLM showed a stronger intensity than its copperchelated form. This is probably due to quenching by copper. This was confirmed by specific interaction between the chelated copper and the bithiazole chromophore shown by ${ }^{1} \mathrm{H}-\mathrm{NMR}$ spectroscopy. That is: a well-resolved ${ }^{1} \mathrm{H}-\mathrm{NMR}$ spectrum of metal-free BLM A2 (0.02 $\mathrm{M}$ in $\mathrm{D}_{2} \mathrm{O}$ at $30^{\circ} \mathrm{C}$, Fig. 3-c) did not change significantly by addition of $10 \%$ molar amount of BLM A $2 \mathrm{Cu}-$ complex except for the bithiazole protons at $\delta$

Fig. 2. Structures of N-acetyl-VI-amide and P-5m<smiles>CO[Al]=NC(C)(C)C</smiles><smiles>Cc1c(N)nc(C(CC(N)=O)NCC(N)C(N)=O)nc1C(=O)NC(Cc1c[nH]cn1)C(=O)NC(C)C(O)C(C)C(=O)NC(C(=O)O)C(C)O</smiles> 
Fig. 3. $100 \mathrm{MHz}{ }^{1} \mathrm{H}-\mathrm{NMR}$ spectra of metal-free BLM A2, Cu-chelated BLM A2 and their mixture at $30^{\circ} \mathrm{C}$

a) Cu-chelated BLM A2 $\left(0.02 \mathrm{M}\right.$ in $\left.\mathrm{D}_{2} \mathrm{O}\right)$

b) metal-free BLM A2: Cu-chelated BLM A2=10:1

c) metal-free BLM A2 $\left(0.02 \mathrm{M}\right.$ in $\left.\mathrm{D}_{2} \mathrm{O}\right)$

The $\mathrm{pH}$ was adiusted to 6.0 before dissolving in $\mathrm{D}_{2} \mathrm{O}$. External TMS reference.

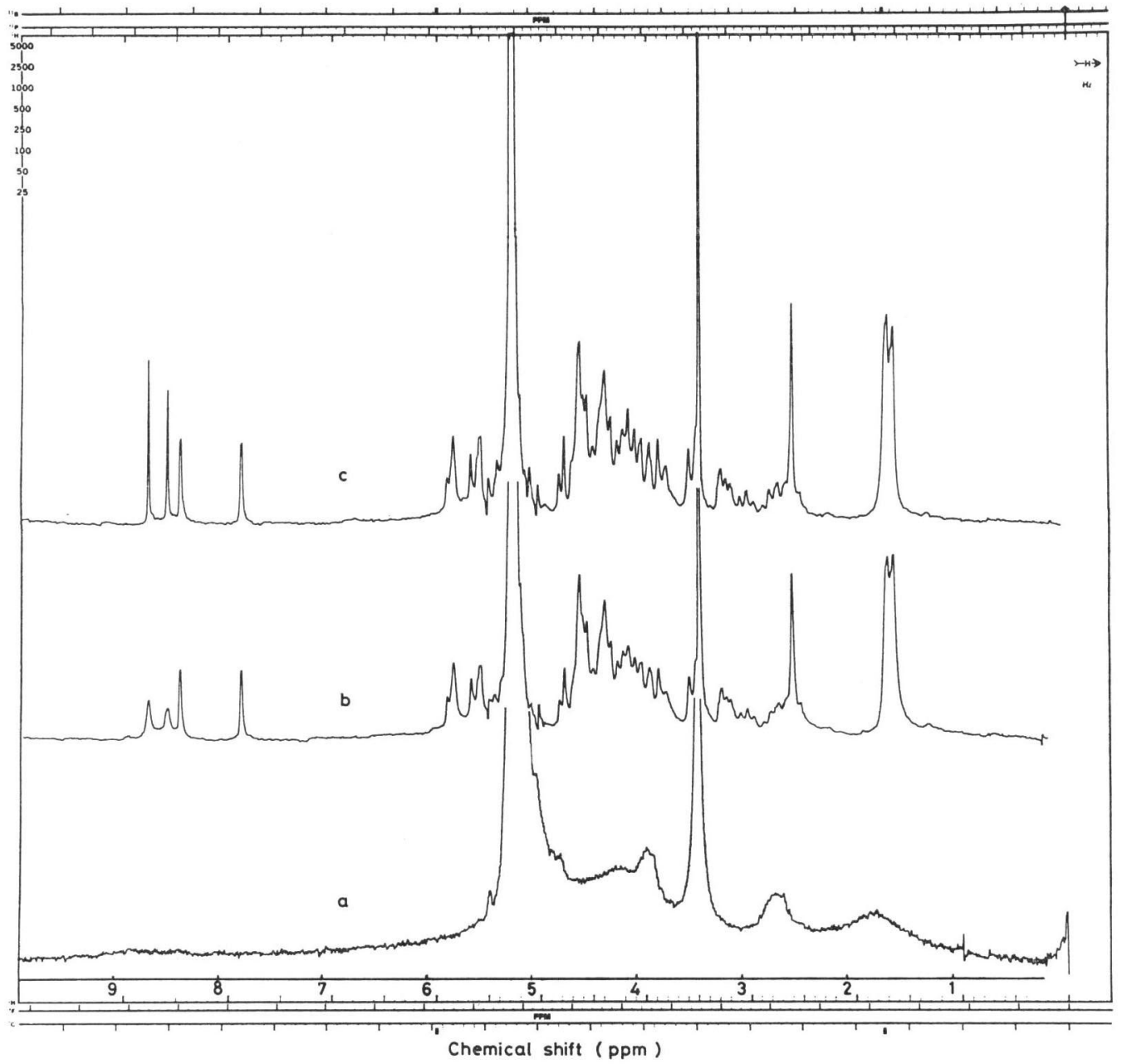

8.49 and 8.68 (external TMS reference) ${ }^{6)}$ which broadened significantly (Fig. 3-b). The broadened signals were sharpened by elevation of the measurement temperature due to increased exchange rate. Incidentally, BLM A2 Cu-complex gave an unresolved broad ${ }^{1} \mathrm{H}-\mathrm{NMR}$ spectrum except for the S-dimethyl signal ( $\delta$ 3.42) of the terminal amine due to paramagnetic effect of the copper (II) (Fig. 3-a).

The difference of fluorescence intensity between N-acetyl-VI-amide and metal-free BLM (Fig. 1) suggested intramolecular quenching in metalfree BLM.
Association constant $(K)$ and maximum binding site $(n)$ of BLMs to nucleic acids were calculated as follows $^{7)}$ : If each binding site of nucleic acids interacts with each BLM molecule with an equal affinity, the association constant, $K$, can be expressed by

$$
K=\frac{[B b]}{(n[P]-[B b])[B f]}
$$

where $[B b],[B f]$ and $[P]$ represent the concentration of bound BLM, free BLM and nucleic acid phosphate; $n$ is the maximum number of binding sites per phosphate of nucleic acid. The equa- 
Fig. 4. Fluorescence quenching at $350 \mathrm{~nm}$ of bleomycins by addition of various amount of calf thymus DNA

Concentration of bleomycins $7.5 \times 10^{-6} \mathrm{M}$, excitation at $310 \mathrm{~nm} .(+)$ means copper-complex and $(-)$ means metal-free.

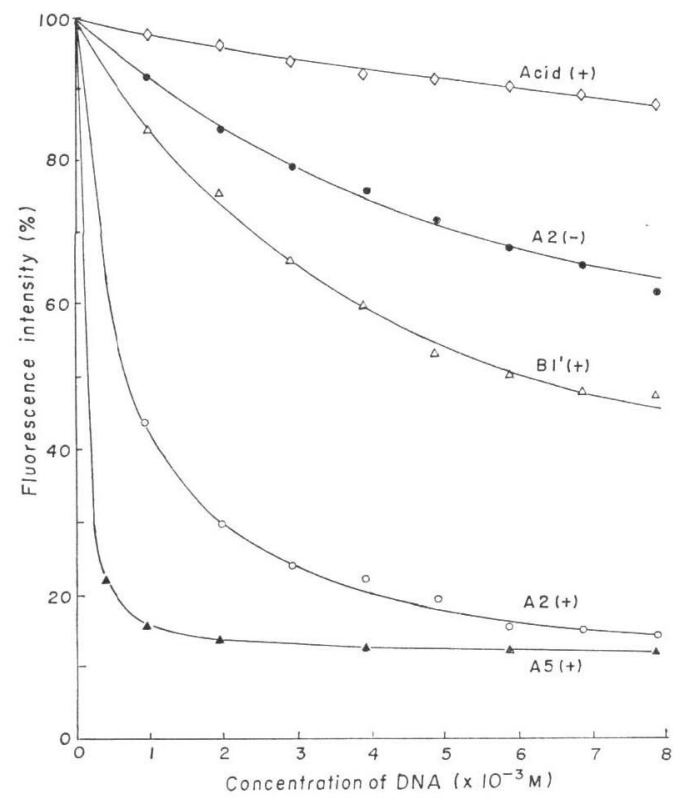

tion (1) can be rearranged to the following:

$$
\frac{1}{[B f]}=K\left(n \frac{[P]}{[B b]}-1\right)
$$

$[B b]$ and $[B f]$ were calculated from equation (3) and (4) as follows:

$$
\begin{aligned}
& {[B b]=\frac{F o-F}{F o-F f}[B]} \\
& {[B f]=\frac{F-F f}{F o-F f}[B]}
\end{aligned}
$$

where $[B]$ represents the total concentration of BLM, $F o, F$ and $F f$ are the observed fluorescence of BLM in the absence, in the presence of an experimental amount and in the presence of an extreme excess amount of nucleic acid.

In the following experiments, the emission intensity at $350 \mathrm{~nm}$ was measured by excitation at $310 \mathrm{~nm}$ to minimize the absorption by nucleic acids. The fluorescence intensity of BLMnucleic acid mixture was corrected by subtracting the fluorescence of blank solution (without BLM), and the fluorescence was measured immediately after mixing BLM and nucleic acid. Addition of calf thymus DNA to BLM quenches the fluores-
Table 1. Association constant $(K)$ and maximum binding site $(n)$ of bleomycins to calf thymus DNA

\begin{tabular}{r|l|l}
\hline Bleomycins & \multicolumn{1}{|c}{$K$} & \multicolumn{1}{|c}{$n$} \\
\hline BLM A5 $(+\mathrm{Cu})$ & $3.0 \times 10^{5}$ & 0.071 \\
BLM A2 $(+\mathrm{Cu})$ & $2.3 \times 10^{5}$ & 0.013 \\
BLM A2 $(-\mathrm{Cu})$ & $3.2 \times 10^{5}$ & 0.0024 \\
BLM B1 $(+\mathrm{Cu})$ & $2.1 \times 10^{5}$ & 0.0034 \\
\hline
\end{tabular}

\begin{tabular}{|c|c|}
\hline Nucleic acids & Quenching $(\%)$ \\
\hline $5^{\prime}-\mathrm{pA}$ & 0 \\
\hline $5^{\prime}-\mathrm{pU}$ & 0 \\
\hline $5^{\prime}-\mathrm{pG}$ & 4 \\
\hline $5^{\prime}-\mathrm{pC}$ & 0 \\
\hline $5^{\prime}-\mathrm{pdG}$ & 5 \\
\hline dG (deoxyguanosine) & 0 \\
\hline G (guanosine) & 0 \\
\hline Calf thymus DNA & 56 \\
\hline Denatured calf thymus DNA* & 65 \\
\hline poly $(\mathrm{dG}-\mathrm{dC})$ & 64 \\
\hline poly $\mathrm{dG} \cdot$ poly $\mathrm{dC}$ & 61 \\
\hline poly $(\mathrm{dA}-\mathrm{d} \mathrm{T})$ & 31 \\
\hline poly $\mathrm{dA} \cdot$ poly $\mathrm{dT}$ & 0 \\
\hline poly $\mathrm{G} \cdot$ poly $\mathrm{C}$ & 51 \\
\hline poly $\mathrm{A} \cdot$ poly $\mathrm{U}$ & 35 \\
\hline poly I·poly $\mathrm{C}$ & 18 \\
\hline$d(p T p G)_{8-9}$ & 29 \\
\hline $\mathrm{d}(\mathrm{pCpA})_{6-9}$ & 13 \\
\hline $\mathrm{d}(\mathrm{pTpG})_{6-9}+\mathrm{d}(\mathrm{pCpA})_{6-9}$ & 32 \\
\hline poly A & 39 \\
\hline poly $U$ & 14 \\
\hline Poly G & 77 \\
\hline poly C & 0 \\
\hline poly dA & 18 \\
\hline poly dT & 20 \\
\hline poly dG & 80 \\
\hline poly $\mathrm{dC}$ & 0 \\
\hline
\end{tabular}

Table 2. Fluorescence quenching of BLM A5 $(+\mathrm{Cu})$ by addition of nucleic acids

* hyperchromicity $31 \%$

Concentrations of BLM $\mathrm{A} 5(+\mathrm{Cu})$ and nucleic acids are $0.075 \times 10^{-4} \mathrm{M}$ and $1.22 \times 10^{-4} \mathrm{M}$ (P), respectively. Excitation at $310 \mathrm{~nm}$, emission at $350 \mathrm{~nm}$.

cence of BLM without changing the emission maximum wave length. The effect of various concentrations of the DNA on the fluorescence of BLMs was studied (Fig. 4). From these fluorescence quenching curves, we obtained $[B b]$ and 
Fig. 5.

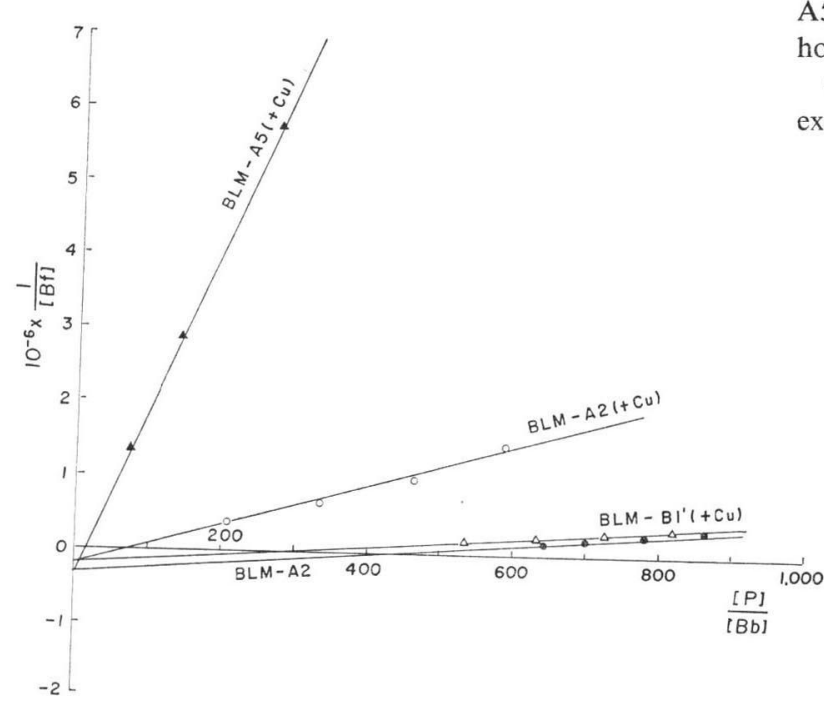

Fig. 6. Fluorescence quenching at $350 \mathrm{~nm}$ of BLM A5 $(+\mathrm{Cu})$ by addition of various amount of ribohomopolymers

Concentration of BLM A5 $(+\mathrm{Cu}) 5.3 \times 10^{-6} \mathrm{M}$, excitation at $310 \mathrm{~nm}$.

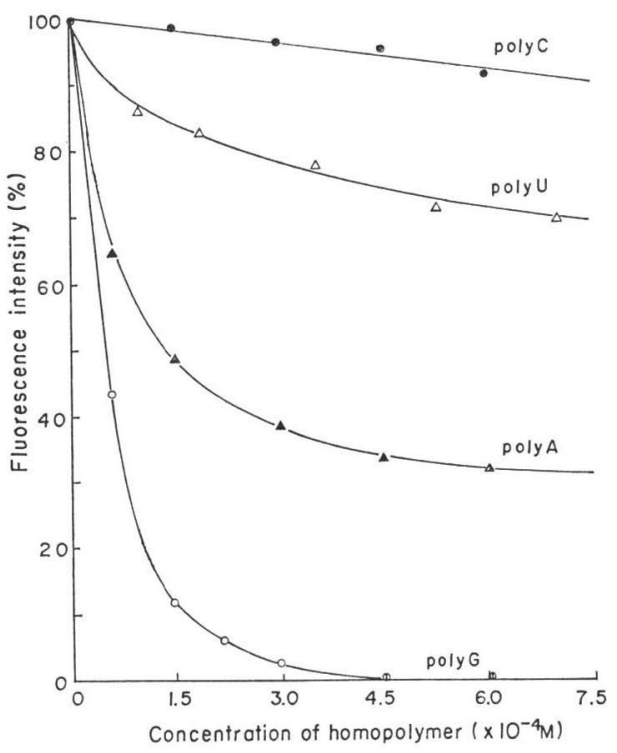

Table 3. Association constant $(K)$ and maximum binding site $(n)$ of BLM $\mathrm{A} 5(+\mathrm{Cu})$ to ribohomopolymers

\begin{tabular}{l|c|c}
\hline Ribohomopolymer & $K$ & $n$ \\
\hline poly G & $5.7 \times 10^{6}$ & 0.038 \\
poly A & $1.0 \times 10^{6}$ & 0.043 \\
poly U & $1.0 \times 10^{5}$ & 0.077 \\
\hline
\end{tabular}

shown that they are not involved in the reactive site of BLM to cleave DNA ${ }^{101}$. CHIEN et al. ${ }^{21}$ suggested from their ${ }^{1} \mathrm{H}-\mathrm{NMR}$ study that BLM binds to DNA most tightly with these two groups. These results suggest that the binding site of BLM to DNA is independent from the reaction site of BLM, leading to strand scission of DNA.

To investigate the binding specificity of BLM to nucleic acids, we compared the quenching rates of copper-chelated BLM A5 by addition of the same quantity of various nucleic acids (Table 2). Copper-chelated BLM A5 was chosen because of the highest sensitivity to the quenching (see Fig. 4) and no damage to nucleic acids ${ }^{9 !}$. Based on these quenching rates, one can roughly estimate the binding strength of BLM to nucleic acids. As shown in Table 2, 5'-mononucleosides except for 5'-GMP did not show any interaction with 
BLM. 5'-GMP showed a weak effect but deoxyguanosine and guanosine did not show the effect. Double-stranded DNAs containing G-C base pairs [poly $(\mathrm{dG}-\mathrm{dC})$, poly $\mathrm{dG} \cdot$ poly dC] had stronger interaction with BLM than those containing A-T base pairs $[$ poly $(\mathrm{dA}-\mathrm{dT})$, poly dA. poly dT]. Heat-denatured calf thymus DNA showed almost the same interaction as the intact double-stranded DNA. Among eight ribo- and deoxyribo-homopolymers poly $\mathrm{G}$ and poly $\mathrm{dG}$ showed the strongest interaction. It was noticed that BLM bound to RNA, although as well known, BLM does not react with RNA.

To establish the relation between these quenching rates and association constants, we studied the fluorescence quenching of copper-chelated BLM A5 by using various amounts of ribohomopolymers, poly $A$, poly $\mathrm{U}$, poly $\mathrm{G}$ and poly $\mathrm{C}$ (Fig. 6). Application of equations (2), (3), (4) gave $K$ - and $n$-values for the binding of BLM A5 to the homopolymers (Fig. 6 and Table 3). The $K$ - and $n$-values for poly $\mathrm{C}$ could not be estimated due to the low quenching rate. This result showed that $K$-value for poly $\mathrm{G}$ is 5.7 times larger than poly A and 57 times larger than poly $\mathrm{U}$, although the $n$-values are in the same order. From Tables 1 and 3, it is deduced that the $K$-value is mainly dependent on nucleic acids and the $n$ value on BLMs.

From all the above-described experimental results, it can be concluded that the binding site of BLM to DNA is independent from the reaction site of BLM leading to strand scission of DNA. The bithiazole part of BLM preferentially binds to guanine base in nucleic acids, and the positive charge at the terminal amine facilitates BLM binding to nucleic acids.

\section{Acknowledgements}

This work was partly supported by a contract from the Division of Cancer Treatment, National Cancer Institute, U.S.A., NO1-CM-57009. The authors are grateful to Dr. A. Matsuyama, National Cancer Center Research Institute, Japan, for helpful discussions.

\author{
Hiroshi Kasai \\ Hiroshi Naganawa \\ TOMOHISA TAKITA \\ HAMAO UMEZAWA
}

Institute of Microbial Chemistry

3-14-23 Kamiosaki, Shinagawa-ku, Tokyo, Japan

(Received September 21, 1978)

\section{References}

1) Umezawa, H.; Y. Suhara, T. Takita \& K. MAEDA: Purification of bleomycins. J. Antibiotics, Ser A 19: 210 215, 1966

2) Chien, M.; A. P. Grollman \& S. B. Horwitz: Bleomycin-DNA interactions: Fluorescence and proton magnetic resonance studies. Biochemistry $16: 3641 \sim 3647,1977$

3) Umezawa, H.; Y. Takahashi, A. Fujil, T. SaIno, T. Shirai \& T. TAKITA: Preparation of bleomycinic acid: Hydrolysis of bleomycin B2 by a Fusarium acylagmatine amidohydrolase. J. Antibiotics 26: 117 119, 1973

4) Takita, T.; A. Fuji, T. Funuoka \& H. UmeZAWA: Chemical cleavage of bleomycin to bleomycinic acid and synthesis of new bleomycins. J. Antibiotics 26: 252 254, 1973

5) Koyama, G.; H. Nakamura, Y. Muraoka, T. Takita, K. Maeda \& H. Umezawa: The chemistry of bleomycin. II. The molecular and crystal structure of a sulfur-containing chromophoric amino acid. Tetrahed. Lett. 1968: 4635 4638, 1968

6) Takita, T.; Y. Muraoka, A. Fujil, H. Itoh, K. Maeda \& H. Umezawa: The structure of the sulfur-containing chromophore of phleomycin, and chemical transformation of phleomycin to bleomycin. J. Antibiotics 25: 197 199, 1972

7) Ichimura, S.; M. Zama, H. Fujita \& T. Ito: The nature of strong binding between acridine orange and deoxyribonucleic acid as revealed by equilibrium dialysis and thermal denaturation. Biochim. Biophys. Acta 190: 116 125, 1969

8) Fujil, A.; T. Takita, K. Maeda \& H. UmeZAWA: Chemistry of bleomycin. XI. The structure of the terminal amines. J. Antibiotics 26: $398 \sim 399,1973$

9) Asakura, H.; M. Hori \& H. Umezawa: Characterization of bleomycin action on DNA. J. Antibiotics 28: 537 542, 1975

10) Takita, T.; Y. Muraoka, T. Nakatani, A. FujiI, Y. IItAKa \& H. Umezawa: Chemistry of bleomycin. XXI. Metal-complex of bleomycin and its implication for the mechanism of bleomycin action. J. Antibiotics 31: 1073 1077, 1978 